University of Wollongong

Research Online

Faculty of Engineering and Information

Faculty of Engineering and Information

Sciences - Papers: Part B

Sciences

2018

Processing, characterization, and in vivo evaluation of poly (L-lactic acid)fish gelatin electrospun membranes for biomedical applications

Mariana Branco

University of Porto

Ana Caseiro

University of Porto

Dina M. Morais Da Silva

University of Wollongong, dsilva@uow.edu.au

Irina Amorim

University of Porto

Alexandra Rema

University of Porto

See next page for additional authors

Follow this and additional works at: https://ro.uow.edu.au/eispapers1

Part of the Engineering Commons, and the Science and Technology Studies Commons

Research Online is the open access institutional repository for the University of Wollongong. For further information contact the UOW Library: research-pubs@uow.edu.au 


\title{
Processing, characterization, and in vivo evaluation of poly (L-lactic acid)-fish gelatin electrospun membranes for biomedical applications
}

\author{
Abstract \\ The development of biomaterials for application in advanced therapies requires thorough characterization \\ of its biological behavior, which ultimately entails in vivo compatibility and performance assays. \\ Electrospun fiber membranes of poly(L-lactic acid) (PLLA) and fish gelatin blends were produced and \\ characterized, coupling the biomechanical features of PLLA with gelatin (GEL) biocompatibility. Fiber \\ diameter was not affected by polymer blending, whereas the swelling degree increased with increasing \\ GEL contents for values up to $566 \pm 13 \%$, behaving as a superhydrophilic material. Human umbilical cord- \\ derived mesenchymal stem cells (hUC-MSCs) adhesion was favored in the PLLA-GEL membranes, and \\ cell viability was not affected after 7 days in culture. Membranes were then evaluated for in vivo \\ biocompatibility through subcutaneous implantation in a rat model, for up to 15 days. No significant \\ differences between the biological behavior of PLLA, PLLA-GEL, and GEL electrospun membranes at 15 \\ days postimplantation were verified, with attained inflammation scores supporting an acceptable tissue \\ response, deeming them fit for further biological assays. This work demonstrates that fiber blends of \\ PLLA and GEL present promising in vitro and in vivo characteristics to be explored for tissue engineering.

\section{Disciplines \\ Engineering | Science and Technology Studies}

\section{Publication Details} \\ Branco, M., Caseiro, A. R., Silva, D. M., Amorim, I., Rema, A., Pedrosa, S. S., Branquinho, M. V., Gomes, P. S., \\ Fernandes, M. H., Santos, J. D., Mauricio, A. C. \& Sencadas, V. (2018). Processing, characterization, and in \\ vivo evaluation of poly (L-lactic acid)-fish gelatin electrospun membranes for biomedical applications. \\ ACS Applied Bio Materials, 1 (2), 226-236.

\section{Authors} \\ Mariana Branco, Ana Caseiro, Dina M. Morais Da Silva, Irina Amorim, Alexandra Rema, Sílvia Pedrosa, \\ Mariana Branquinho, Pedro S. Gomes, Maria H. Fernandes, J D. Santos, Ana Mauricio, and Vitor Sencadas
}


Published as: Branco, M., Caseiro, A. R., Silva, D. M., Amorim, I., Rema, A., Pedrosa, S. S., Branquinho, M. V., Gomes, P. S., Fernandes, M. H., Santos, J. D., Mauricio, A. C. \& Sencadas, V. (2018). Processing, characterization, and in vivo evaluation of poly (Llactic acid)-fish gelatin electrospun membranes for biomedical applications. ACS Applied Bio Materials, 1 (2), 226-236.

Processing, characterization and in-vivo evaluation of PLLA-fish gelatin electrospun membranes for biomedical applications

Mariana Branco ${ }^{a}$, Ana R. Caseiro ${ }^{b, c, d}$, Dina M. Silva ${ }^{e}$, Irina Amorim ${ }^{f, g}$, Alexandra Rêma ${ }^{f}$, Sílvia S. Pedrosa ${ }^{b, c}$, Mariana V. Branquinhob,c Pedro S. Gomes ${ }^{d, h}$, Maria H. Fernandes ${ }^{d, h}$, José D. Santos ${ }^{\mathrm{a}, \mathrm{d}}$, Ana C. Mauricio ${ }^{\mathrm{b}, \mathrm{c}^{*}}$, Vitor Sencadas ${ }^{\mathrm{e}, \mathrm{i}^{*}}$

a Faculdade de Engenharia, U. Porto, Rua Dr. Roberto Frias, 4200-465 Porto, Portugal.

${ }^{\text {b }}$ Departamento de Clínicas Veterinárias, Instituto de Ciências Biomédicas de Abel Salazar (ICBAS), Universidade do Porto (UP), Rua de Jorge Viterbo Ferreira, no 228, 4050-313 Porto, Portugal.

c Centro de Estudos de Ciência Animal (CECA), Instituto de Ciências, Tecnologias e Agroambiente da Universidade do Porto (ICETA), Rua D. Manuel II, Apartado 55142, 4051-401, Porto, Portugal.

d REQUIMTE/LAQV - Universidade do Porto, Departamento de Engenharia Metalúrgica e Materiais, Faculdade de Engenharia, Universidade do Porto, Rua Dr. Roberto Frias, s/n, 4200-465 Porto, Portugal.

e School of Mechanical, Materials, Mechatronics and Biomedical Engineering, University of Wollongong, Wollongong, NSW 2522, Australia.

${ }^{f}$ Departamento de Patologia e Imunologia Molecular, Instituto de Ciências Biomédicas de Abel Salazar (ICBAS), Universidade do Porto (UP), Rua de Jorge Viterbo Ferreira, no 228, 4050-313 Porto, Portugal.

g i3S - Instituto de Investigação e Inovação em Saúde, Universidade do Porto, R. Alfredo Allen, 4200-135 Porto, Portugal.

h Faculdade de Medicina Dentária, Universidade Do Porto (FMDUP), 4200-393 Porto, Portugal.

i ARC Center of Excellence for Electromaterials Science, University of Wollongong, 2522 NSW, Australia.

\section{${ }^{*}$ Corresponding authors:}

\section{Vitor Sencadas}

Email: victors@uow.edu.au; vsencadas@gmail.com 


\title{
Ana Colette Maurício
}

Email: acmauricio@icbas.up.pt, ana.colette@hotmail.com

Keywords: Electrospun membranes, Poly(L-lactic acid)-fish gelatin blends, Wettability, Biomimetic extracellular matrix, Biocompatibility

\begin{abstract}
:
The development of biomaterials for application in advanced therapies requires thorough characterization of its biological behavior, which ultimately entails in vivo compatibility and performance assays. Electrospun fiber membranes of poly(L-lactic acid) (PLLA) and fish gelatin bends were produced and characterized, coupling the biomechanical features of PLLA with gelatin (GEL) biocompatibility. Fiber diameter was not affected by polymer blending, whereas the swelling degree increased with increasing GEL contents for values up to $566 \pm 13 \%$, behaving as a superhydrophilic material. Human umbilical cord-derived mesenchymal stem cells (hUC-MSCs) adhesion was favored in the PLLA-GEL membranes, and cell viability was not affected after 7 days in culture. Membranes were then evaluated for in vivo biocompatibility through subcutaneous implantation in a rat model, for up to 15 days. No significant differences between the biological behavior of PLLA, PLLA-GEL and GEL electrospun membranes at 15 days post-implantation was verified, with attained inflammation scores supporting an acceptable tissue response, deeming them fit for further biological assays. This work demonstrates that fiber blends of PLLA and GEL present promising in vitro and in vivo characteristics to be explored for tissue engineering.
\end{abstract}




\section{Introduction}

Tissue engineering (TE) is an interdisciplinary field that aims to design functional substitutes for damaged tissues, ${ }^{1-2}$ by manufacturing substitutes able to mimic natural tissue environment, matching closely the mechanical, structural, and functional native properties. ${ }^{1}$ There is still a demand for effective biomaterials for scaffolds' fabrication that gather the desired features of processability, cytocompatibility, biocompatibility, biodegradability, surface chemistry, macro- and microstructure and mechanical properties. $^{3}$ From that perspective, native extracellular matrix (ECM) represents the ideal scaffold, consisting of a complex mesh of interconnected fibrous proteins (> $90 \%$ collagen), proteoglycans and growth factors..$^{4-5}$ Indeed, the clinical relevance of ECM is reflected by the number of commercially available biological devices, consisting of decellularized ECM from several sources and tissues, which are supplied as sheets, gels, putty, powder or granule forms. ${ }^{6-10}$

Despite the good clinical outcomes, the use of biological grafts from allo- and xenogeneic sources often raises some concerns associated to the host response and the risk of disease transmission. ${ }^{10}$ The processing steps of decellularization, disinfection and sterilization strongly minimize the likelihood of an adverse host reaction, but small amounts of DNA fragments were still detected in commercial products after treatment and there is a lack of standardization regarding the threshold for cell remnants. ${ }^{11-12}$ Furthermore, the processing methodologies also compromise the mechanical strength of the scaffold. ${ }^{8}$ An alternative approach is to design biomimetic platforms, resembling the fiber array of native ECM, and that could provide mechanical support for the host cells.

In that sense, electrospinning is a suitable technique to manufacture biomimetic micro and nanosized fibers by applying an electrical field to a polymeric droplet. Owing to the structural features, electrospun fiber membranes mimic the fiber array and the network of interconnected pores of ECM, thus favoring the adhesion, proliferation and even differentiation of various cell types, such as human mesenchymal stem cells, ${ }^{13}$ osteoblasts, ${ }^{14-15}$ hypothalamus A59 nerve cells, ${ }^{16}$ and fibroblasts. ${ }^{17}$

Poly(L-lactic acid) (PLLA), an aliphatic polymer that has gained attention because of its biocompatibility, processability, and mechanical properties. ${ }^{18-19}$ The polymer degradation occurs via hydrolysis and takes several months to be completed in vitro, 
which is explained by the hydrophobic behavior displayed by PLLA with a contact angle between 70 and $85^{\circ}$, for films and scaffolds $20-22$ and $120-142^{\circ}$ for electrospun membranes, depending on fiber orientation. ${ }^{14-15,20}$

Different strategies had been applied to modify the surface properties of synthetic polymers, either by chemical or physical treatments. Chemical methods usually damage both the surface and the bulk of the material and generate chemical wastes, ${ }^{23}$ while plasma treatments are only effective at the surface of the material, but sample size is limited to the laboratorial scale. ${ }^{23-24}$ Synthetic polymers blended with natural ones, is a milder and more effective way of improving overall hydrophilicity and thus increasing cell-polymer interaction. ${ }^{25}$

Gelatin is a collagen-derived biocompatible and biodegradable polymer, which is also available from non-mammalian sources. ${ }^{26}$ However, when used as a single component, originates scaffolds with poor mechanical properties due to its high solubility in water. ${ }^{27}$ Studies on electrospun mats from polymeric blends using gelatin demonstrated higher in vitro proliferation rates of endothelial cells, ${ }^{28}$ favoring bone marrow-derived stromal cells attachment, proliferation and ingrowth ${ }^{29}$ and enhancing nerve differentiation and neurite outgrowth. ${ }^{30}$ Moreover, the presence of $25 \%$ collagen in poly( $\varepsilon$-caprolactone) substrates enhanced Schwann cell migration and axonal regeneration. ${ }^{31}$

The biocompatibility assessment for a material is dependent on material-host interactions, individual's variability and local of implantation rather than the intrinsic features of the material itself. ${ }^{32}$ Local host reactions upon biomaterial implantation are known, in which acute and chronic inflammation are characterized by typical features related to the cellular population at the implant vicinity. ${ }^{33-34}$

Several studies reported the fabrication of PLLA-gelatin membranes, which often claims their potential for biomedical applications or for tissue engineering ${ }^{35-39}$. However, most of those works lacks the in vivo experiments and are limited to in vitro characterization using cell lines. Indeed, the poor biological correlation between the traditional in vitro methodologies and the host response after implantation of biomaterials are well known. The study by Chen et al. ${ }^{38}$ reported the potential for ectopic cartilage formation of cationized gelatin grafted onto plasma-treated PLLA nanofiber constructs, at 4 weeks post-implantation; however, this study lacks the evaluation of the local inflammatory 
response after implantation, being the inflammatory cells only qualitatively evaluated by its presence/absence.

This work reports the fabrication of electrospun fiber membranes by blending PLLA and fish-derived gelatin (GEL). Mesenchymal stem cells from umbilical cord (hUC-MSCs) were used to study the cytocompatibility of the developed membranes and the assessment of the inflammatory reaction after subcutaneous implantation was performed using a rat model. Our work provides new insight into the host response upon implantation of PLLA-gelatin nanofiber structures, with a thorough characterization of the inflammatory response developed locally and a qualitative evaluation of potential systemic toxicity. The developed membranes have potential for tissue engineering applications, since both cytocompatibility and biocompatibility were confirmed.

\section{Experimental}

\subsection{Materials}

Poly(L-lactic acid) (PLLA, Purasorb PL18, Corbion) was supplied by Corbion, fish gelatin (GEL), 1,1,1,3,3,3-hexafluoroisopropanol (HFIP, analytical grade > 99 purity), and glutaraldehyde solution (GA; 50 wt.\%), where purchased from, Sigma-Aldrich and used as received.

\subsection{Electrospinning}

PLLA and gelatin were dissolve at room temperature in HFIP with a concentration of $10 \%$ ( w/v, Table 1), with the help of a magnetic stirrer. Afterwards, a glass syringe fitted with a metallic blunt needle $(\varnothing=0.5 \mathrm{~mm}$ ) was filled with the liquid solution. Processing was performed by applying an electric field of $1.5 \mathrm{kV} \cdot \mathrm{cm}^{-1}$ with a dc power supply (Gamma High Voltage). The constant feed rate of $0.5 \mathrm{ml}^{-1} \mathrm{~h}^{-1}$ was controlled by a syringe pump (KDScientific). Fibers were collected in a grounded flat aluminum plate placed $20 \mathrm{~cm}$ apart from the needle. All experiments were performed at $21 \pm 2 \stackrel{\circ}{ }$ with a relative humidity of $43 \pm 5 \%$. 
Table 1: Description of membranes developed according to the weight ratio of PLLA and GEL.

\begin{tabular}{ccc}
\hline Sample & PLLA (w/w) & GEL $(\mathbf{w} / \mathbf{w})$ \\
\hline PLLA & 100 & 0 \\
PG 3:1 & 75 & 25 \\
PG 1:1 & 50 & 50 \\
PG 1:3 & 25 & 75 \\
GEL & 0 & 100 \\
\hline
\end{tabular}

\subsection{Cross-linking}

A beaker filled with $20 \mathrm{~mL}$ of GA solution was placed on the bottom of a dissector chamber in the presence of the samples. Vacuum was applied to create a GA saturated atmosphere and cross-link the protein material for $48 \mathrm{~h}$, as represented in Scheme 1.

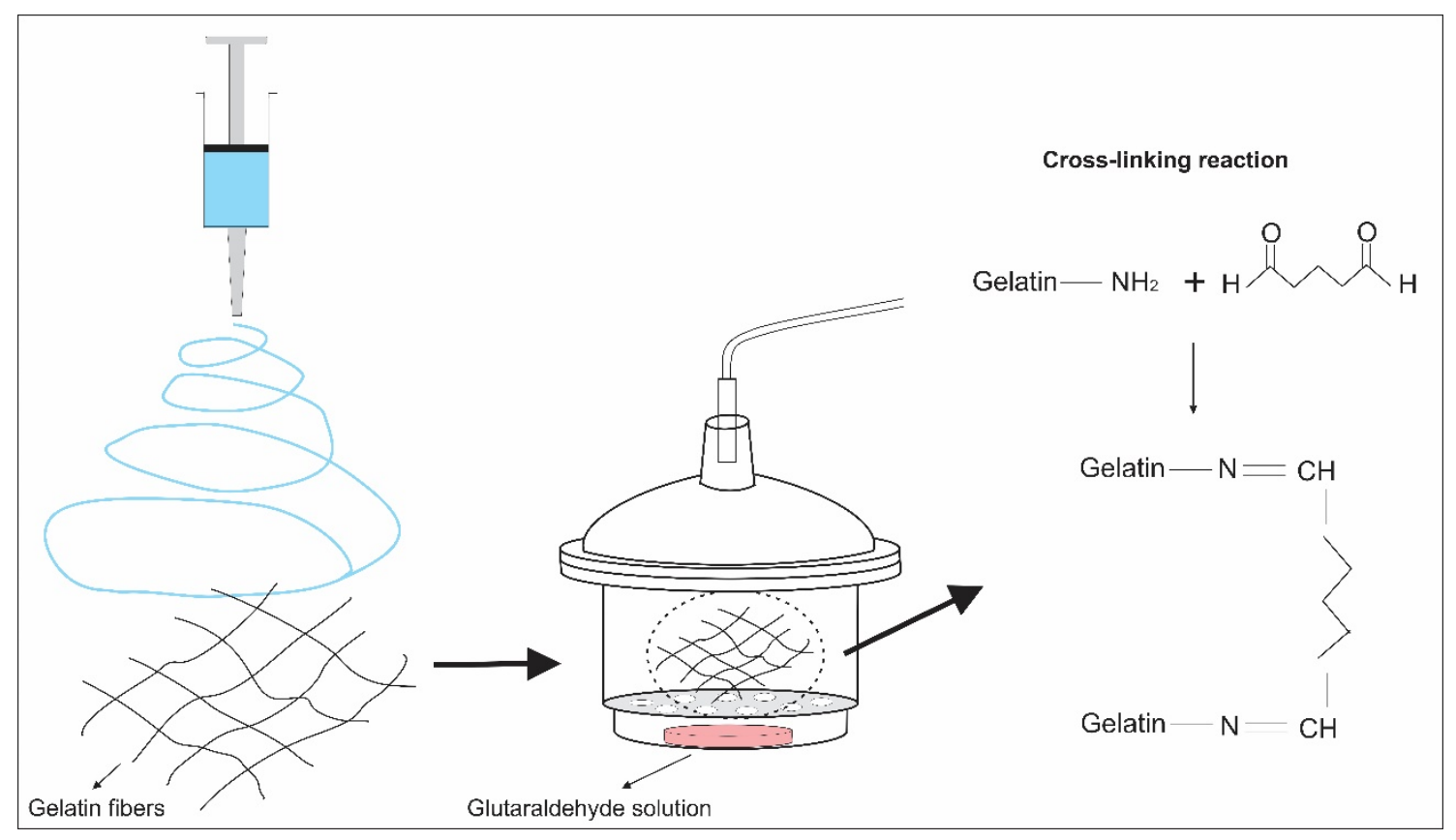

Scheme 1: Preparation of the PLLA-GEL electrospun membranes, followed by crosslinking in a vapor chamber. 


\subsection{Membrane characterization}

Scanning electron microscopy (SEM) from JEOL (JSM-6000 Neoscope, at an accelerating voltage of $15 \mathrm{kV}$ ) was used to study the sample morphology. A thin layer of gold was previously sputtered (Smart Coater, JEOL) onto the surface of the samples. Sample average fiber diameter distribution was calculated by measuring approximately 100 fibers using the Image J software. ${ }^{40}$

Water contact angle (WCA) was performed at room conditions in a Data Physics OCA20 device. A droplet of ultra-pure water ( $3 \mu \mathrm{L}$, Milli-Q, Millipore) was deposited on the surface of the samples and the contact angle was acquired using a DataPhysics OCA 35 goniometer and SCA20 software. Results were obtained by measuring eight different locations of each sample.

Thermal stability was measured by thermogravimetric analysis (TGA, TGA4000 from Perkin-Elmer) under inert atmosphere (nitrogen gas flow) at a heating rate of 20 ㄷ. $\mathrm{min}^{-}$ 1. A Netzsch DSC 214 Polyma apparatus was used to record the differential scanning calorimetry measurements. The samples were cut from the middle region of the fibrous mats and placed into aluminum pans ( $40 \mu \mathrm{L}$ with pinhole lid). The heating rate used was $10 \stackrel{\circ}{ } \mathrm{C} \cdot \mathrm{min}^{-1}$, and a nitrogen purge was used.

A Shimadzu IRAffinity-1S coupled with an attenuated total reflectance (ATR) accessory was used to collect the samples infrared spectra, from 4000 to $600 \mathrm{~cm}^{-1}$, after 32 scans and a resolution of $2 \mathrm{~cm}^{-1}$. All experiments were performed at room temperature.

Mechanical properties were evaluated by measuring the stress-strain data in tensile mode, using a Shimadzu Universal Testing Machine (EZ-L mechanical tester, fitted with a $10 \mathrm{~N}$ load cell) at a rate of $1 \mathrm{~mm} \cdot \mathrm{min}^{-1}$. Samples were cut into dog bone shape $(2 \mathrm{~mm}$ $\mathrm{x} 18 \mathrm{~mm}$, and $50 \mu \mathrm{m}$ thickness) and the experiments were performed at room temperature. The Young Modulus (E) was calculated in the linear region between 0 and $1 \%$ of strain. Results are presented as the average and the standard deviation of 5 individual experiments.

\subsection{Degree of swelling}


Water uptake was measured by immersing the fiber mats in deionized water, followed by wiping the excess of water with a piece of tissue paper. The degree of swelling was calculated through equation 1:

$$
\text { Degree of Swelling }(\%)=\left[\frac{W-W_{d}}{W_{d}}\right] \times 100
$$

where $W$ and $W_{d}$ are the weight of the soaked and dried sample, respectively.

\subsection{In vitro cytocompatibility evaluation}

\subsubsection{Membrane sterilization}

Electrospun membranes used in the biological assays were cut in disks of $13 \mathrm{~mm}$ in diameter and were sterilized by ultraviolet exposure for 30 minutes for each side of the membrane.

\subsubsection{Cell culture}

Human mesenchymal stem cells from umbilical cord (hUC-MSCs) were purchased from PromoCell (Cat. C-12971; Lot No. 1112304.2), cultured in MEM $\alpha$, GlutaMAX' ${ }^{\mathrm{TM}}$, no nucleosides media (Gibco), supplemented with fetal bovine serum (10\% v/v), penicillin (100 IU/mL), streptomycin $(0.1 \mathrm{mg} / \mathrm{mL})$, amphotericin $B(2.05 \mu \mathrm{g} / \mathrm{mL})$ and HEPES $(10 \mathrm{mM})$, and maintained at $37^{\circ} \mathrm{C}$, in a $5 \% \mathrm{CO}_{2}$ humidified atmosphere.

\subsubsection{Cell viability}

PLLA, GEL and PLLA-GEL (PG 1:1) disks were placed onto 24-well plates using Teflon inserts (inner diameter=7.8 $\mathrm{mm}$ ) to prevent membranes from floating and preincubated with culture media for $48 \mathrm{~h}$. Cells were then seeded at a density of $8 \times 10^{4}$ cells/well and wells without the membranes were used as controls.

Cell viability was measured at day 1, 3 and 7 using PrestoBlue ${ }^{\mathrm{TM}}$ (Invitrogen, A13262), a resazurin-based assay, as per manufacturer's protocol. Briefly, cells were incubated for $1 \mathrm{~h}$ in fresh medium containing PrestoBlue ${ }^{\mathrm{TM}}$ cell viability reagent $(10 \% \mathrm{v} / \mathrm{v})$, at each time point. The absorbance read at $570 \mathrm{~nm}$ was normalized to the $595 \mathrm{~nm}$ values and 
the corrected absorbance was obtained by the subtraction of averaged control wells to each experimental well. Results were expressed as a percent reduction of PrestoBlue ${ }^{\mathrm{TM}}$ reagent, using equation 2 , following manufacturer specifications:

$$
\% \text { reduction of PrestoBlue }=\frac{(O 2 \times A 1)-(O 1 \times A 2)}{(R 1 \times N 2)-(R 2 \times N 1)} \times 100
$$

where 01 and 02 are the molar extinction coefficient of oxidized PrestoBlue ${ }^{\mathrm{TM}}$ at 570 and $595 \mathrm{~nm}$, respectively; $R 1$ and $R 2$ are the molar extinction coefficient of reduced PrestoBlue $^{\mathrm{TM}}$ at 570 and $595 \mathrm{~nm}$, respectively; $A 1$ and $A 2$ are the absorbance of test wells at 570 and $595 \mathrm{~nm}$, respectively; $N 1$ and $N 2$ are the absorbance of media only wells at 570 and $595 \mathrm{~nm}$, respectively.

For cell morphology evaluation, adherent cells on the membranes were immersed in a formaldehyde / PBS solution (4\% v/v) for $20 \mathrm{~min}$ at room temperature, dehydrated and analyzed under SEM microscope (Quanta 400 FEG), after Au/Pd sputtering (SPI Module Sputter Coater).

\subsection{In vivo experiments}

In vivo procedures were approved by the ICBAS-UP Animal Welfare Organism (ORBEA) and by the Veterinary Authorities of Portugal, under European (2010/63/EU) and Portuguese (DL 113/2013) Directives.

\subsubsection{Surgical procedure}

Sasco Sprague Dawley rats were purchased from Charles River Laboratories (Barcelona, Spain) and acclimatized for two weeks prior to surgery. Before subcutaneous implantation, animals were anesthetized by intraperitoneal injection of a xylazine/ketamine mixture.

A total of six linear incisions (10-15 mm) were performed in both sides of the animals' dorsal region for membrane implantation. Sham surgical procedures left devoid of membranes were the most caudal incisions. On day 3, 7, and 15 post-implantation, 
animals were placed under deep anesthesia, sacrificed by intracardiac injection and the tissues from the implanted area were collected for histological evaluation. A thorough necropsy was performed by a veterinary, to assess for systemic effects of the implanted biomaterial, and specimens from the liver, spleen, kidneys, lungs, heart, and thymus were collected for histopathological analysis.

\subsubsection{Histological analysis}

Samples were routinely processed for histopathological analysis, and sequential sections $(3 \mu \mathrm{m})$ were accurately evaluated after Hematoxylin-Eosin (H\&E) staining, using a Nikon microscope (Nikon Eclipse E600).

The local effects of the implanted membranes were evaluated by an experienced veterinary pathologist for the identification and grading of the inflammatory cells populations surrounding the implanted biomaterial, as well as evaluating concurrent events, such as the presence of giant cells, necrosis, fibrosis, and local angiogenesis, following the guidelines of the International Standard ISO $10993-6$ (Annex E). ${ }^{41}$ Individual scores enabled the semi-quantitative classification of the implants as: nonirritant (0.0 - 2.9), slight irritant (3.0 - 8.9), moderate irritant (9.0 - 15.0) or severe irritant $(>15) \cdot{ }^{41}$

\subsection{Data analysis}

Statistical differences were determined by one-way analysis of variance (ANOVA) with a Tukey post-test for multiple comparisons (GraphPad Prism, v.6.01, USA). For the viability assay, results were presented as mean \pm standard deviation (SD) of quadruplicates, whereas results from global histological scores were presented as mean \pm standard error of the mean (SEM). A value of $p<0.05$ was considered statistically significant.

\section{Results and Discussion}

\subsection{Electrospun fiber morphology}


Figure $1(a-i)$ presents the characteristic morphology of the electrospun membranes made either from GEL ( $a$ and $b$ ), or its blends with PLLA ( $c-h)$, and pure PLLA (i). Beadfree fibers were produced from a solution of $10 \mathrm{wt} \%$ GEL or PLLA and therefore, this polymer concentration was fixed for the PLLA and gelatin blends (Table 1). Thereafter, defect-free and smooth electrospun fibers were generated successfully for all the prepared samples, and in stable conditions (figure 1).

The average fiber diameter was measured with Image $\mathrm{J}$ software ${ }^{40}$ and is presented in figure 1 (j). Pristine PLLA and GEL fibers had an average diameter of $285 \pm 59 \mathrm{~nm}$ and $292 \pm 37 \mathrm{~nm}$, respectively. Moreover, when the fish gelatin was added to the solution, no substantial changes in the electrospun fiber average diameter were observed by replacing the PLLA for equal amounts of GEL. Also, GEL incorporation did not affect the spinnability of the solution, which is known to be mainly affected by the polymer concentration, among other factors. ${ }^{42-43}$

GEL is a water-soluble polymer and it dissolves almost immediately when placed with aqueous media or body fluids. To broaden the applicability of the GEL electrospun fibers for tissue and biomedical engineering applications, the samples were cross-linked with glutaraldehyde. After exposure to a saturated atmosphere of GA, it was observed an increase between 10 - 18\% in the fiber average diameter for all the PLLA-GEL fibers, as well as for the pristine GEL electrospun fibers (Figure 1j). Notwithstanding, no significant differences were found between formulations or conditions submitted or not to crosslinking.

Contradictory studies can be found in the literature regarding the effect of the GA on the gelatin fiber average diameter. An increase of GEL fiber diameter from $443 \pm 101 \mathrm{~nm}$ up to $2069 \pm 865 \mathrm{~nm}$ was reported when the electrospun mat was exposed to GA. ${ }^{44}$ Other work showed that gelatin electrospun fiber average dimeter increases between 10 and $24 \%$, when exposed to the GA, ${ }^{45}$ which is in accordance with our results. Overall, it was reported that when GA is used in a saturated vapor atmosphere, it doesn't seem to greatly influence the fiber morphology and average distribution. ${ }^{46-47}$

Gelatin cross-linking comprises the reaction the GA aldehyde groups and the $\varepsilon$-amino groups of lysine or arginine of the polypeptide chain by a Schiff base reaction ${ }^{48}$, and is associated with a change of membrane color, from white to pale yellow. 


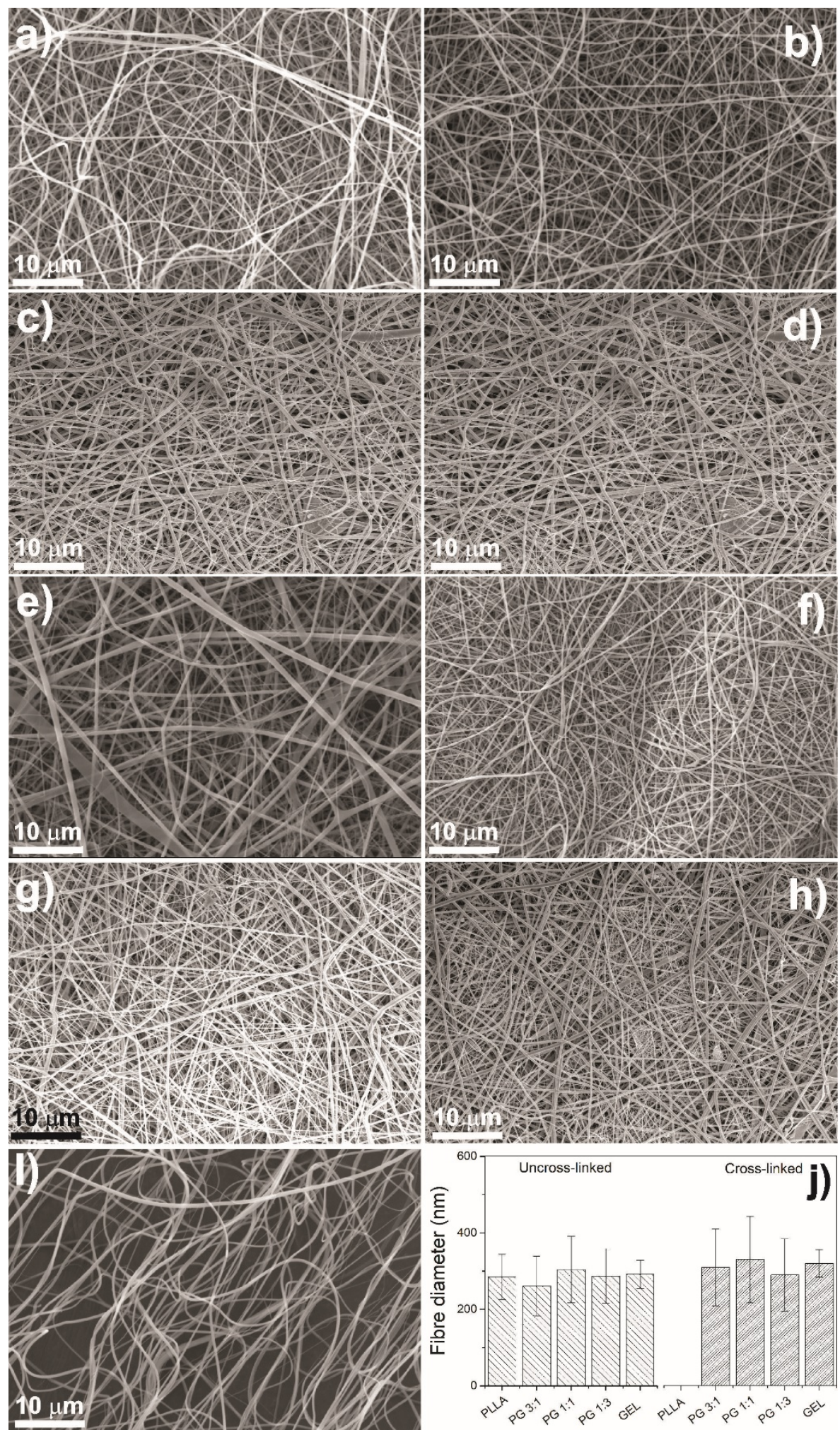

Figure 1: PLLA-GEL electrospun membranes: a) and b) Uncross-linked and cross-linked GEL, c) and d) PG 1:3 uncross-linked and cross-linked sample, e) and f) PG 1:1 uncrosslinked and cross-linked, g) and h) PG 3:1 uncross-linked and cross-linked, i) PLLA electrospun mat, and j) influence of the GEL content in the overall average fiber diameter, before and after cross-linking with GA. 


\subsection{Wettability and Swelling properties}

Sample wettability is fundamental to promote cell adhesion and proliferation. ${ }^{49-50}$ PLLA electrospun membranes present a water contact angle (WCA) of $136 \pm 1^{\circ}$, characteristic of a hydrophobic behavior, and is attributable to the overall roughness of the fiber membranes. ${ }^{51-52}$ On the other hand, cross-linked GEL is a superhydrophilic material, presenting a WCA of $0^{\circ}$, which means that it can readily uptake the aqueous media (Figure 2a). When the gelatin was added to the PLLA solution, it was observed that the membranes with lower gelatin content (PG 3:1) had a WCA like the one observed for PLLA. Nevertheless, for the PG 1:1 and PG 1:3 samples, a WCA of $0^{\circ}$ was observed, and the membrane absorbed almost instantaneously the water droplet that was deposited on its surface (Figure 2a). This behavior is probably due to the amount of GEL protein available in the electrospun fibers that can uptake the water.

In a previous work, it was demonstrated that nanofibrous PLLA-gelatin membranes could improve substrate wettability. Kim et al. ${ }^{35}$ showed a decrease of the WCA from $135^{\circ}$ measured for pure PLLA, down to $50^{\circ}$, observed for a sample with the same mass ratio of gelatin and PLLA (PG 1:1). In their work, they couldn't obtain clear and smooth fibers for higher gelatin concentrations (PG 1:3), and they used uncross-linked gelatin samples, which would dissolve almost immediately when the water was placed in contact with the fibrous membranes. Similarly, co-electrospun PLLA-gelatin composite nanofibrous mats were developed by Yang et al. ${ }^{53}$ While PLLA and PG 3:1 electrospun membranes presented a strong hydrophobic behavior $\left(W C A=123^{\circ}\right)$, the samples with higher amount of gelatin content exhibit improved wettability and became superhydrophilic after a few seconds. Our results demonstrate that blending PLLA with gelatin in the same solvent, resulted in an improved hydrophilicity of the electrospun membranes, which could improve cell affinity and spreading. ${ }^{35,49,54}$

Due to the hydrophobic nature of PLLA, the water uptake capability of the membrane was negligible (Figure 2b). However, for the blended samples, an increase in the degree of swelling occurred, which correlates with the increase of gelatin added to the electrospun membrane, reaching $674 \pm 12 \%$ for the pure gelatin sample (Figure $2 b$ ); hence, the amount of aqueous media uptake may be related with the amount of GEL that was present in the electrospun membrane. 
Our results showed an improvement of the swelling ability when compared to the structures developed by Nagiah et al. ${ }^{55}$ It was showed that the swelling ability of the PLLA:Gel fibrous membranes was $168 \pm 24 \% .{ }^{55}$ Moreover, this difference could be due to the amount of gelatin present in the electrospun membranes, i.e. the increasing of the swelling ratio increases with the presence of the protein concentration.

The swelling behavior of the developed PLLA-gelatin membranes suggests that they could act like hydrogel materials in aqueous environments.
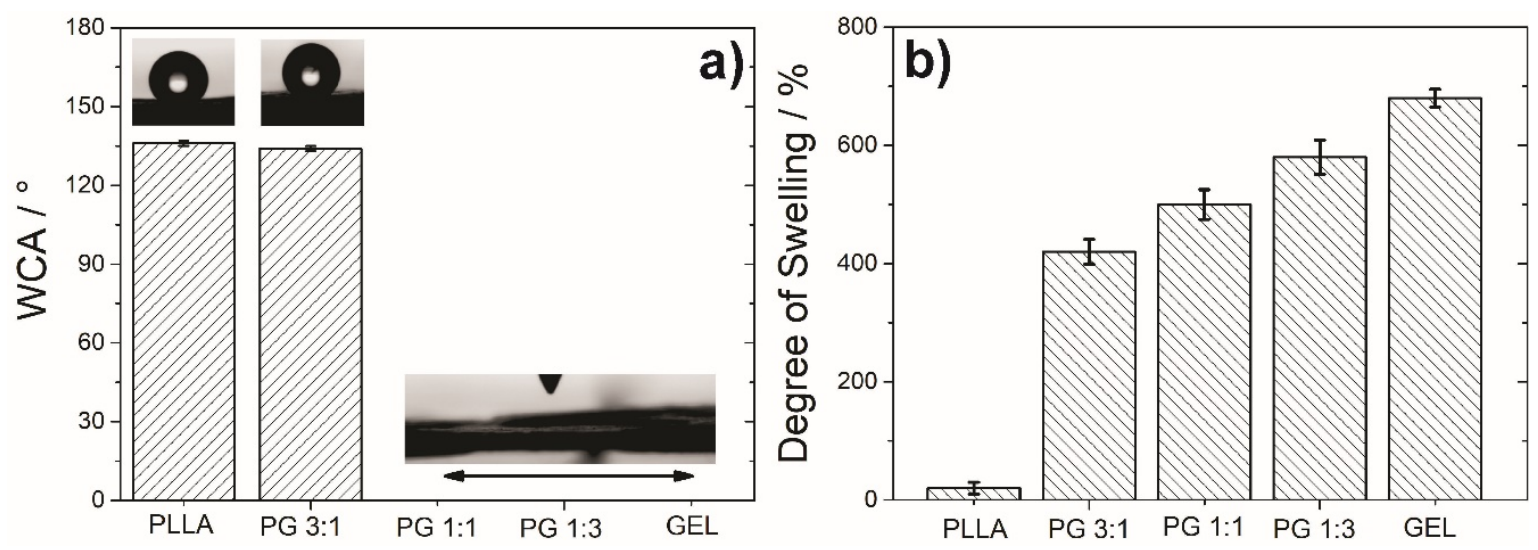

Figure 2: a) Evolution of the WCA, and b) Degree of swelling for the PLLA, PLLA:PG and GEL electrospun membranes.

\subsection{Chemical, thermal and mechanical characterization}

Figure 3 presents the ATR-FTIR spectra obtained for PLLA-gelatin membranes. PLLA presents the ester carbonyl group $(v(C=O))$ vibration band at $1749 \mathrm{~cm}^{-1}$, and the bands at 1183 and $1044 \mathrm{~cm}^{-1}$ are assigned to the amorphous $v(\mathrm{C}-\mathrm{O}-\mathrm{C})+\mathrm{ras}_{a s}\left(\mathrm{CH}_{3}\right)$ and $v\left(\mathrm{C}-\mathrm{CH}_{3}\right)$, respectively. ${ }^{14,56-57}$ Furthermore, pure gelatin presents the amide I and amide II absorption bands at $1640 \mathrm{~cm}^{-1}$ ( $C=O$ stretching), and $1545 \mathrm{~cm}^{-1}(N-H$ bend, and $C-H$ stretch), respectively. The absorption band of the amide III ( $C-N$ stretch plus $N-H$ in phase bending) is observed at $1240 \mathrm{~cm}^{-1} .54,58$ The blends of the PLLA-GEL present the characteristic bands of the individual pristine polymers, and no new absorption band appears, nor the established ones were totally suppressed, suggesting that there is a limited interaction between PLLA and gelatin. 


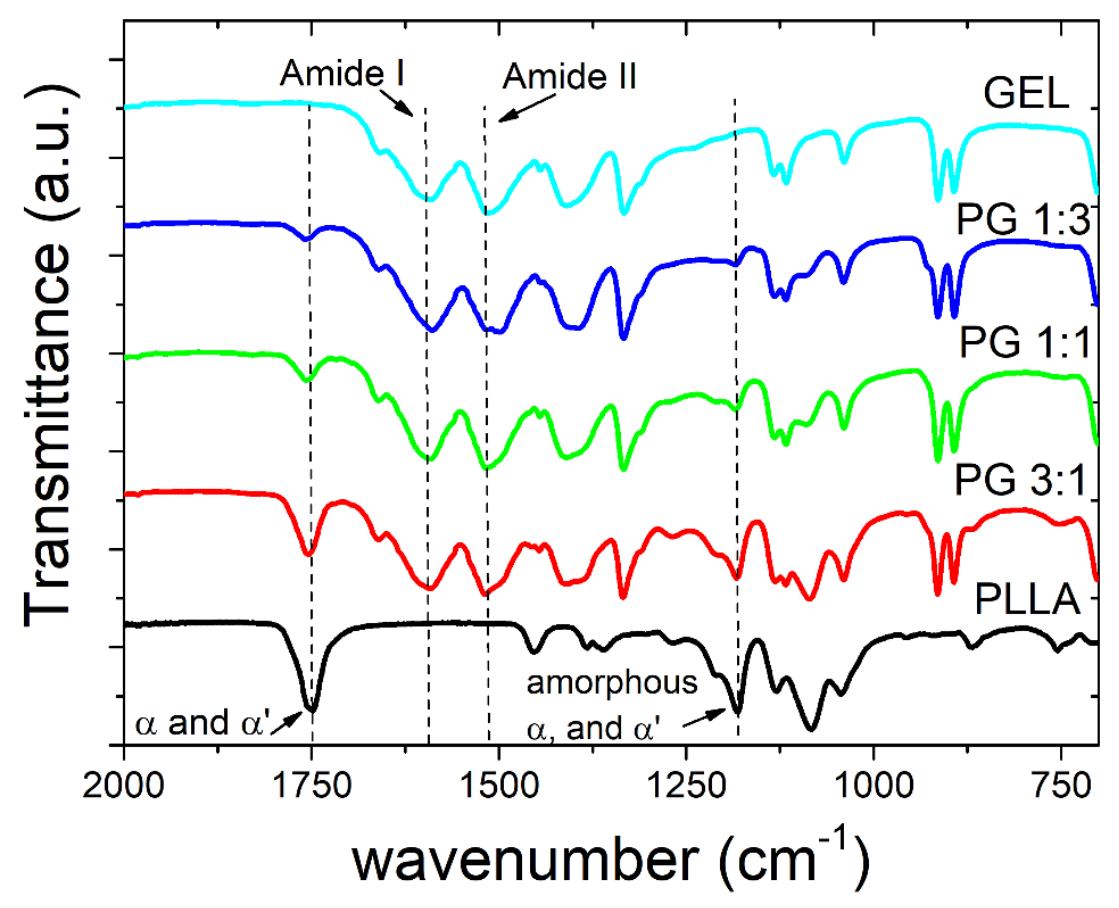

Figure 3: FTIR spectra of the electrospun PLLA-GEL samples.

DSC thermograms show the different thermal transition processes present in the individual polymers and their blends (Figure 4a). PLLA presents a glass transition $\left(T_{g}\right)$ near $60^{\circ} \mathrm{C}$, followed by cold crystallization temperature $\left(T_{c c}\right)$ with minima at $96^{\circ} \mathrm{C}$, and a melting temperature $\left(T_{m}\right)$ with maxima at $154{ }^{\circ} \mathrm{C}$. Furthermore, GEL electrospun fibers present a broad transition at temperatures below $120^{\circ} \mathrm{C}$, which is due to bounded water evaporation that was previously adsorbed by the protein fiber membrane when stored at room conditions.

The PLLA-GEL blends showed the characteristic thermal transitions process of the individual polymers. Nevertheless, a decrease in the $T_{g}$ and $T_{m}$ of the PLLA with increased GEL amount was noticed (Table 2). This behavior suggests limited interaction between the PLLA and GEL during the dissolution and electrospinning process. ${ }^{55}$ Nagiah et al. ${ }^{58}$ suggested that a decrease of the melting temperature of the poly(3hydroxybutyric acid) (PHB) present in the core of a coaxial gelatin-PHB fibers was due to an increased temperature and pressure within the walls of gelatin shell, that led to a decrease of the melting temperature of PHB.

Yan et al. ${ }^{16,59}$ showed that it is possible to electrospin coaxial fibers just by blending PLLA and poly(glycerol sebacate) in the same solution, without the need of a coaxial needle. In this work, GEL and PLLA were dissolve in a common solvent and electrospun with a 
regular blunt needle, allowing GEL to wrap the PLLA, in a similar fashion to a coaxial fiber, leading to an increased pressure within the walls of GEL and a decrease of the PLLA $T_{g}$ and $T_{m}$ thermal transitions.
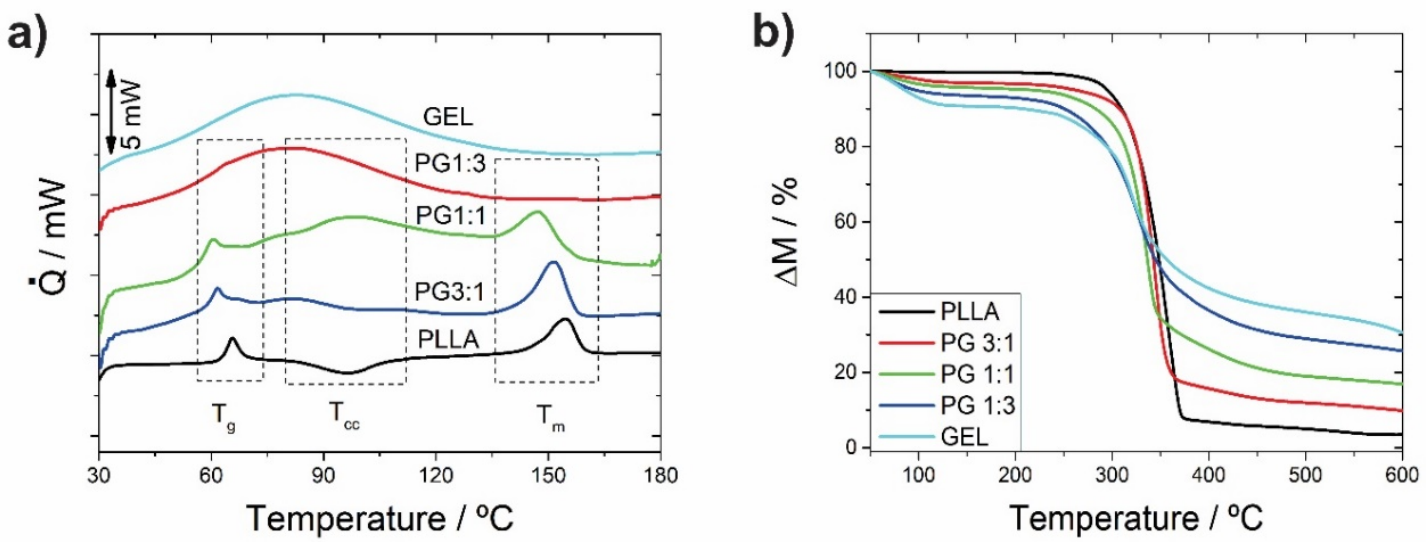

c)

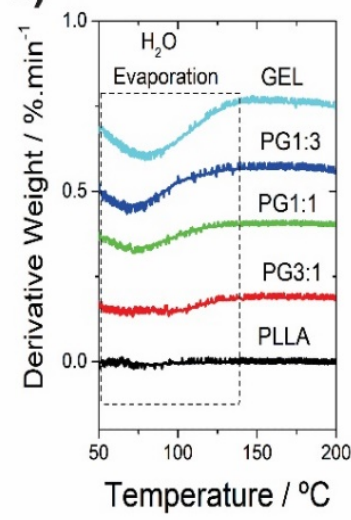

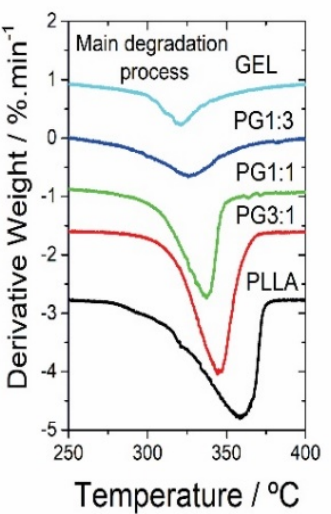

d)

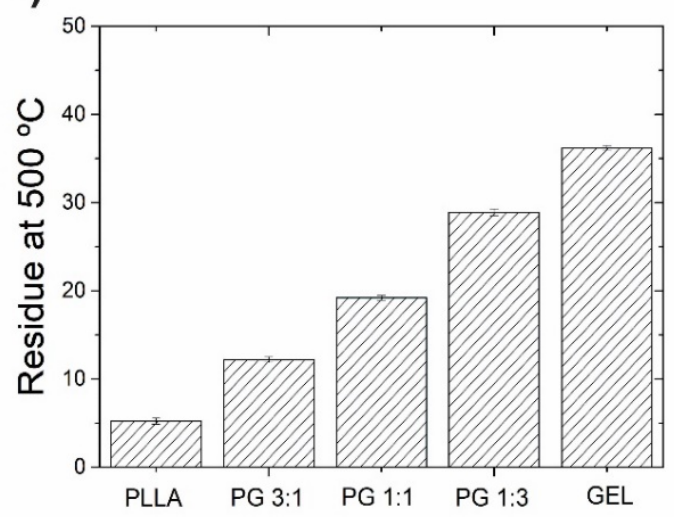

Figure 4: Thermal properties of the PLLA-GEL samples: a) DSC thermogram, b) TGA degradation profile, c) derivative of the weight loss with temperature, and d) residual weight recorded at $500{ }^{\circ} \mathrm{C}$.

PLLA thermal degradation profile presents a single degradation transition, with maxima at $359{ }^{\circ} \mathrm{C}$ (Figure $4 \mathrm{~b}$ and $\mathrm{c}$ ). On the other hand, GEL presents an initial weight loss at temperatures below $140{ }^{\circ} \mathrm{C}$, due to bounded water evaporation, also noticed in the DSC results (Figure 4a). Protein thermal degradation process can be observed at temperatures between $200-500{ }^{\circ} \mathrm{C}$, resulted from the broken amide and imide bonds. ${ }^{47,58}$ PLLA - GEL blends derivative of the weight loss presents a peak temperature 
$\left(T_{\text {peak }}\right)$ in a temperature range between GEL and PLLA (Table 2), which corroborates the limited interaction between the two constituent polymers.

The residue calculated at $500{ }^{\circ} \mathrm{C}$, increases with the GEL content present in the blended membranes (Figure 4d).

Table 2: Description of membranes developed according to the weight ratio of PLLA and GEL.

\begin{tabular}{ccccc}
\hline Sample & $\begin{array}{c}\boldsymbol{T}_{\boldsymbol{g}} \\
\left({ }^{\circ} \mathrm{C}\right)\end{array}$ & $\begin{array}{c}\boldsymbol{T}_{\boldsymbol{c c}} \\
\left({ }^{\circ} \mathrm{C}\right)\end{array}$ & $\begin{array}{c}\boldsymbol{T}_{\boldsymbol{m}} \\
\left({ }^{\circ} \mathrm{C}\right)\end{array}$ & $\begin{array}{c}\boldsymbol{T}_{\text {peak }} \\
\left({ }^{\circ} \mathrm{C}\right)\end{array}$ \\
\hline PLLA & 65 & 96 & 154 & 359 \\
PG 3:1 & 61 & 96 & 151 & 346 \\
PG 1:1 & 61 & - & 147 & 339 \\
PG 1:3 & - & - & - & 327 \\
GEL & - & - & - & 321 \\
\hline
\end{tabular}

The mechanical performance for different electrospun membranes was assessed by quasi-static measurements in a universal testing machine (representative stress-strain curves in Figure S1). GEL electrospun membranes presented a brittle behavior with a strain at break $\left(\varepsilon_{\text {break }}\right)$ limited to $5.1 \pm 1.2 \%$ (Table 3 ). However, it also presented the highest Young modulus $(E)$ and stress at break $\left(\sigma_{\text {break }}\right)$.

On the other hand, PLLA presented a ductile behavior, when compared to the pristine gelatin samples (Table 3), while the samples of PG1:1 presented an intermediate behavior between the pure GEL and the PLLA, in agreement with previous studies. ${ }^{28,60}$ These results showed that blending a synthetic polymer and a natural protein seems to enhance the mechanical support capacity and biomechanical characteristics of the membranes. 
Table 3: - Mechanical properties recorded for the electrospun membranes.

\begin{tabular}{cccc}
\hline Sample & $\boldsymbol{\sigma}_{\text {break }}(\mathrm{MPa})$ & $\boldsymbol{\varepsilon}_{\text {break }}(\%)$ & $\boldsymbol{E}(\mathrm{MPa})$ \\
\hline PLLA & $1.5 \pm 0.2$ & $46.3 \pm 6.1$ & $10.3 \pm 1.3$ \\
GEL & $4.1 \pm 0.2$ & $5.1 \pm 1.2$ & $116.7 \pm 7.7$ \\
PG1:1 & $4.2 \pm 1.2$ & $31.1 \pm 8.7$ & $73.5 \pm 13.1$ \\
\hline
\end{tabular}

\subsection{Cell viability}

Cell viability was evaluated by a direct contact assay, using the PrestoBlue ${ }^{\mathrm{TM}}$ reduction test, to evaluate hUC-MSCs metabolic activity up to 7 days (Figure 5a). The formulation PLLA-GEL (1:1) was selected due to its hydrophilic properties, by opposition to the $3: 1$ ratio, while presenting acceptable mechanical behavior. Cell adhesion on PLLA membranes seemed to be the most challenging with a significant decrease of the PrestoBlue reduction assay after $24 \mathrm{~h}$, as comparing to control. This behavior can be attributed to the hydrophobic character of this polymer; indeed, both GEL and PLLA-GEL composite membranes presented viability values comparable to the control, for the same time point. Subsequently, cells proliferated actively on all compositions, over the 7 days, as observed by the increase in PrestoBlue ${ }^{\mathrm{TM}}$ reduction levels, mitigating the initial adhesion effects on PLLA. After 7 days, no significant differences on the metabolic activity of the cultures were identified between experimental groups and control, although a slight increased value was detected on the PLLA-GEL samples. Our results support the cytocompatible behavior of the polymeric membranes, which agrees with the literature. ${ }^{18-19,22}$

Cell morphology was evaluated by SEM observation of the hUC-MSCs seeded membranes after 7 days of culture (Figure $5 b-d$ ). Microphotographs showed adherent and spread cells on all membrane surfaces (Figure 5 b, c, d), and low magnification images (insets) revealed a continuous cell layer at this culture time. hUC-MSCS presented a well flattened morphology with filopodia stemming towards and along the polymeric fibers, indicating that the electrospun membrane morphology is capable of guiding cell extensions (Figure $5 b^{\prime}, d^{\prime}$ ). Comparatively, cells grown on PLLA-GEL were 
found to present an increased cytoplasmic spreading, and to protrude longer and thicker filopodia (Figure $5 \mathrm{~d}^{\prime}$ ), as those grown on the pristine polymeric membranes (Figure 5 $\left.b^{\prime}\right)$.

Previous research has demonstrated the capability of different cell populations to attach firmly, with filopodial extension, on gelatin-PLLA scaffolds prepared with different ratios. ${ }^{61-62}$ Filopodia can readily extend or retract from the cell membrane, surpassing the limits of the cell into a vacant region, being associated with an investigative behavior of the cellular leading edge. Being a consequence of the contractile machinery activation, filopodial extensions effectuate substrate probing and initiate cell-to-cell interactions, collecting spatial, topographic and chemical information from the surface microenvironment. ${ }^{63-64}$ Filopodia have also been associated to a priming behavior for the establishment of more mature cell-substrate interactions, proceeding to generate mature focal adhesions, following a coherent and sequential process which involves the recruitment of other focal adhesion complex components. ${ }^{65}$ The maturation of adhesion complexes allows integrin gathering and grouping of actin filaments into organized stress fibers, a cellular activity important for cell survival and subsequent proliferation and differentiation processes. ${ }^{66}$

As described above, SEM images are suggestive of a better cell to fiber interaction on the PLLA-GEL mats when compared to the PLLA membrane. The enhanced hydrophilicity of the PLLA-GEL membrane is a key contributor to this behavior, as also reported in previous studies addressing the response of several cell types on PLLA-gelatin blends. ${ }^{28-}$ 30 

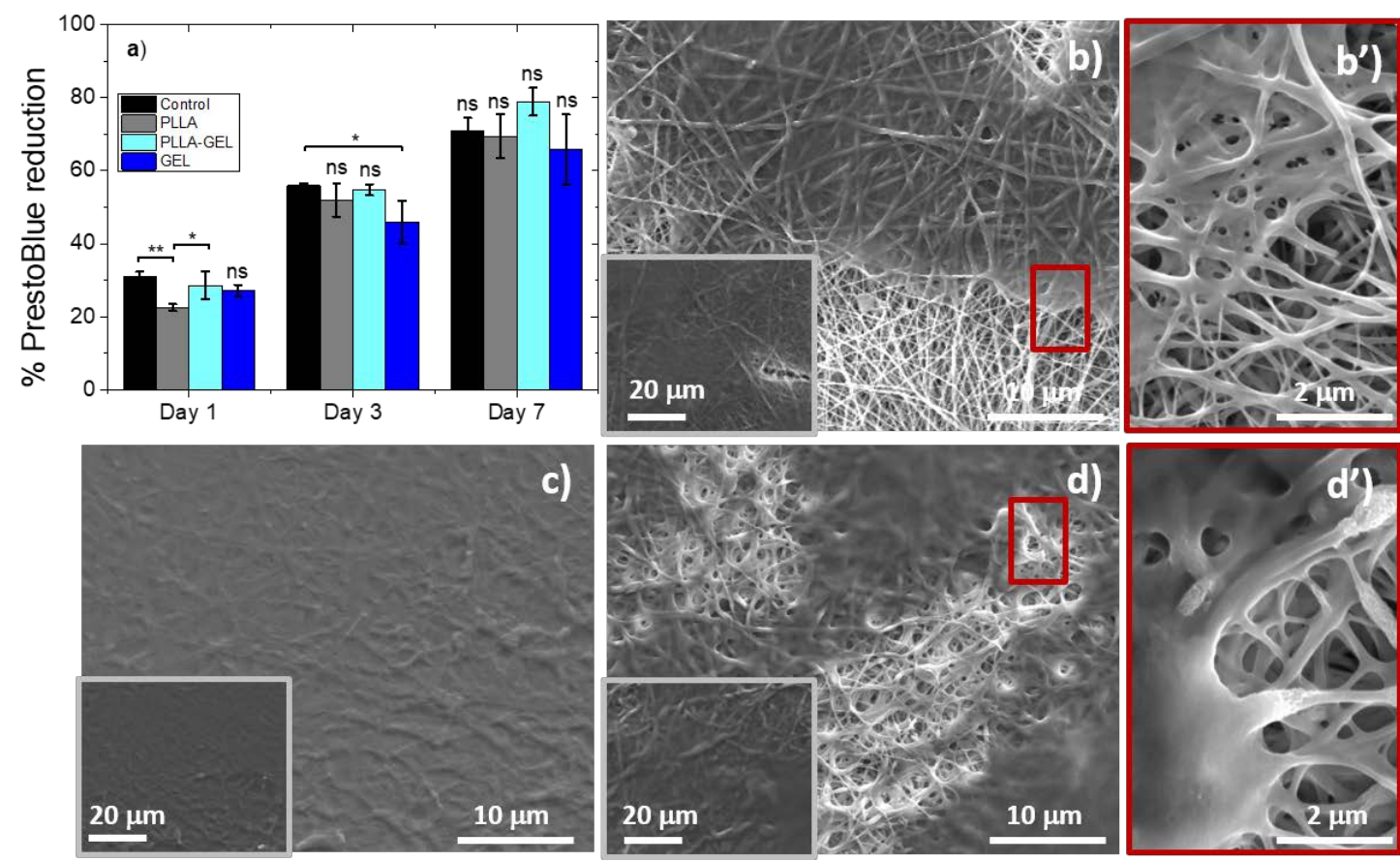

Figure 5: Cell viability (a) evaluated by the percentage of reduction of PrestoBlue ${ }^{\mathrm{TM}}$ reagent using hUC-MSCs seeded in PLLA, PLLA-GEL and GEL membranes up to 7 days; control: cells cultured on standard tissue culture plates. Results are presented as mean \pm SD (ns- nonsignificant; ${ }^{*} p<0.05 ;{ }^{*} p<0.01$ ). SEM microphotographs of hUC-MSCS cultured for 7 days on the (b, b') PLLA, (c) GEL, and (d, d') PG 1:1 fiber membranes. Insets depict low magnification images of the cell layer grown on the membranes.

\subsection{In-vivo evaluation}

Biocompatibility is the first requirement that any biomaterial must comply. As such, the study of biomaterial-host interaction provides an insight of the implant success.

The local effects after implantation for the electrospun membranes were evaluated using a semi-quantitative approach after histological assessment. ${ }^{41}$ Representative images of the histological analysis of PLLA, PLLA-GEL, and GEL implants, and control surgery sites are depicted in Figure 6. 


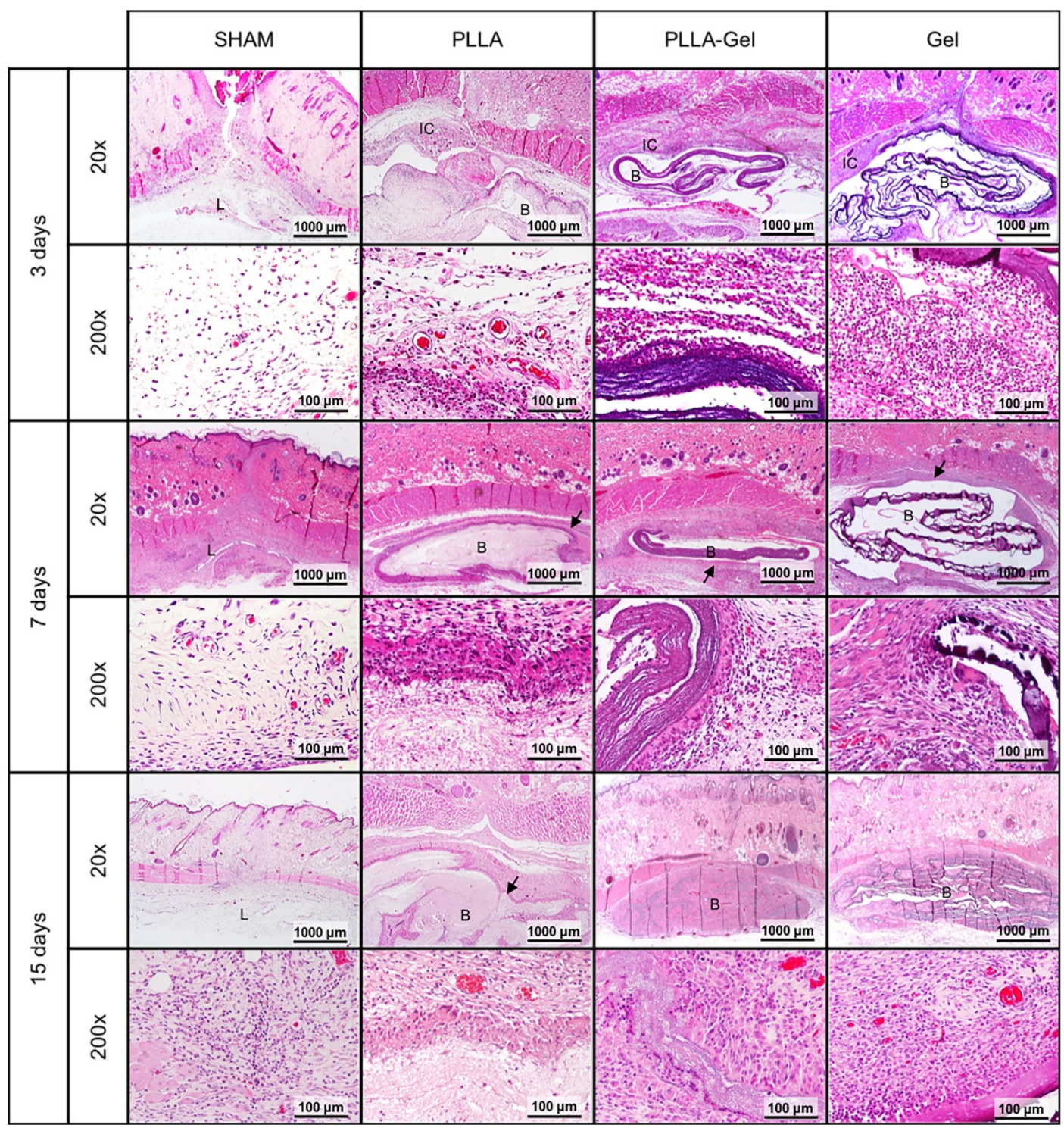

Figure 6: Representative photographs of the histological analysis of PLLA, PLLA-Gelatin, and GEL implants, and Sham surgery sites after 3,7 and 15 days of subcutaneous implantation stained with hematoxylin-Eosin (H\&E). The regions of interest were marked with (L) for lesion site in SHAM samples, (B) Biomaterial, (IC) inflammatory cells and arrow for fibrous capsule.

After 3 days of subcutaneous implantation, evaluated electrospun membranes recorded a mild inflammatory response. The PLLA and PLLA-GEL groups were scored as "nonirritant" whereas GEL scored as 'slight irritant', presenting the only significant difference from sham group (Figure 7a). For the 7 days analysis, all groups elicited inflammatory reaction which was significant when compared with the sham, with emphasis to the 
PLLA membranes (Figure 7b). At the final timepoint, a clear difference in PLLA and GEL groups was observed, due to increased net reaction to the GEL biomaterial (Figure 7c). However, all groups remained 'slight irritant' in terms of inflammatory reaction quantification.
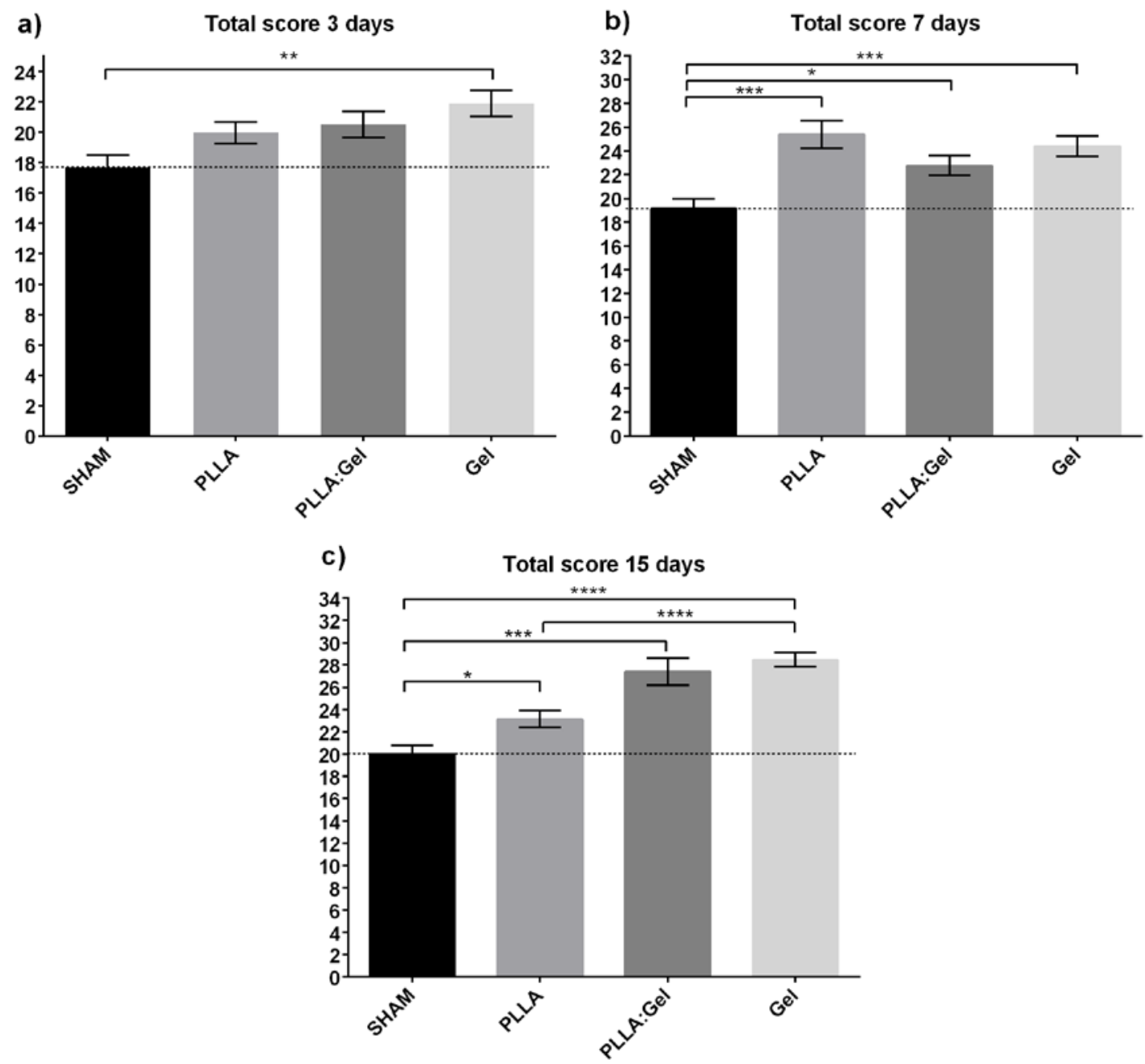

Figure 7: Global histological scores of the PLLA, PLLA-GEL and GEL implants after a) 3, b) 7 , and c) 15 days of subcutaneous implantation versus control surgery sites ( ${ }^{*} p<0.05$; $\left.{ }^{* *} p<0.01 ;{ }^{* * *} p<0.001 ;{ }^{* * * *} p<0.0001\right)$.

A more in-depth analysis revealed that, at day 3, PLLA elicit a subacute inflammatory response, with a predominance of neutrophils (Figure 8). However, at day 7, this is the only experimental group in which the number of neutrophils persists, despite the increase in mononuclear inflammatory cells and fibrosis, suggesting that the 
inflammatory reaction is progressing more slowly to chronicity compared to PLLA-GEL and GEL groups.

At day 7, the PLLA-GEL and GEL groups behave identically showing, in comparison with the previous time point, a clear reduction of polymorphonuclear cells, increase of mononuclear inflammatory cells (macrophages and lymphocytes) and formation of granulation tissue with abundant microvessel organization. In accordance, GEL addition to structured electrospun PLLA membranes, has been previously found to improve dermal tissue repair, further enhancing the angiogenic process. ${ }^{67}$

It should be noted that, at day 15, all groups showed evidence of macrophages and multinucleated giant cells, supporting an active phagocytic process, and could be attributed to the continued presence of material remnants at this time point, undergoing biodegradation. Additionally, minor events of necrosis were identified in the PLLA group being further reduced by the presence of GEL. This observation can be assigned to the increased structural rigidity of PLLA material when compared to the hydrated GEL and PLLA-GEL groups, that are mechanical less resistant than the pristine PLLA membrane. Furthermore, during degradation, PLLA originates acidic products that, in excess, may induced cytotoxic events leading to necrosis. ${ }^{68}$ The addition of GEL may modulate the biodegradation process, contributing to an improved biological response, as previously demonstrated. In accordance, co-electrospun gelatin-poly(L-lactic acid) membranes were found to induce an adequate tissue response, being mechanically and biologically more suitable for the repair of dura mater defects than collagen membranes, in a canine model. ${ }^{62}$ Also, gelatin-grafted electrospun PLLA membranes, implanted for 8 weeks in an animal model of tendon repair, revealed an improved healing outcome regarding collagen organization and fibrocartilage formation, as comparing to the use of PLLA alone. ${ }^{69}$ Despite the initial inflammatory activation verified at early time points - as verified in the present study - following 8 weeks, membranes were resorbed and were found to enhance tissue repair.

Another interesting observation is the differential staining of the implanted biomaterials upon histological processing, which can be commented considering its $\mathrm{pH}$, wettability and swelling properties. The PLLA membranes presented a pale color, while PLLA-GEL and GEL groups depict increased H\&E staining. Haematoxilyn is an acidophilic stain that binds acidic or basophilic structures. ${ }^{70}$ Gelatin's inherent composition may contribute to 
this differential color uptake. Otherwise, it could be related to the increase biofluids uptake by the GEL groups. The hydrophobic nature of PLLA prevents material swelling when placed in the biological systems.

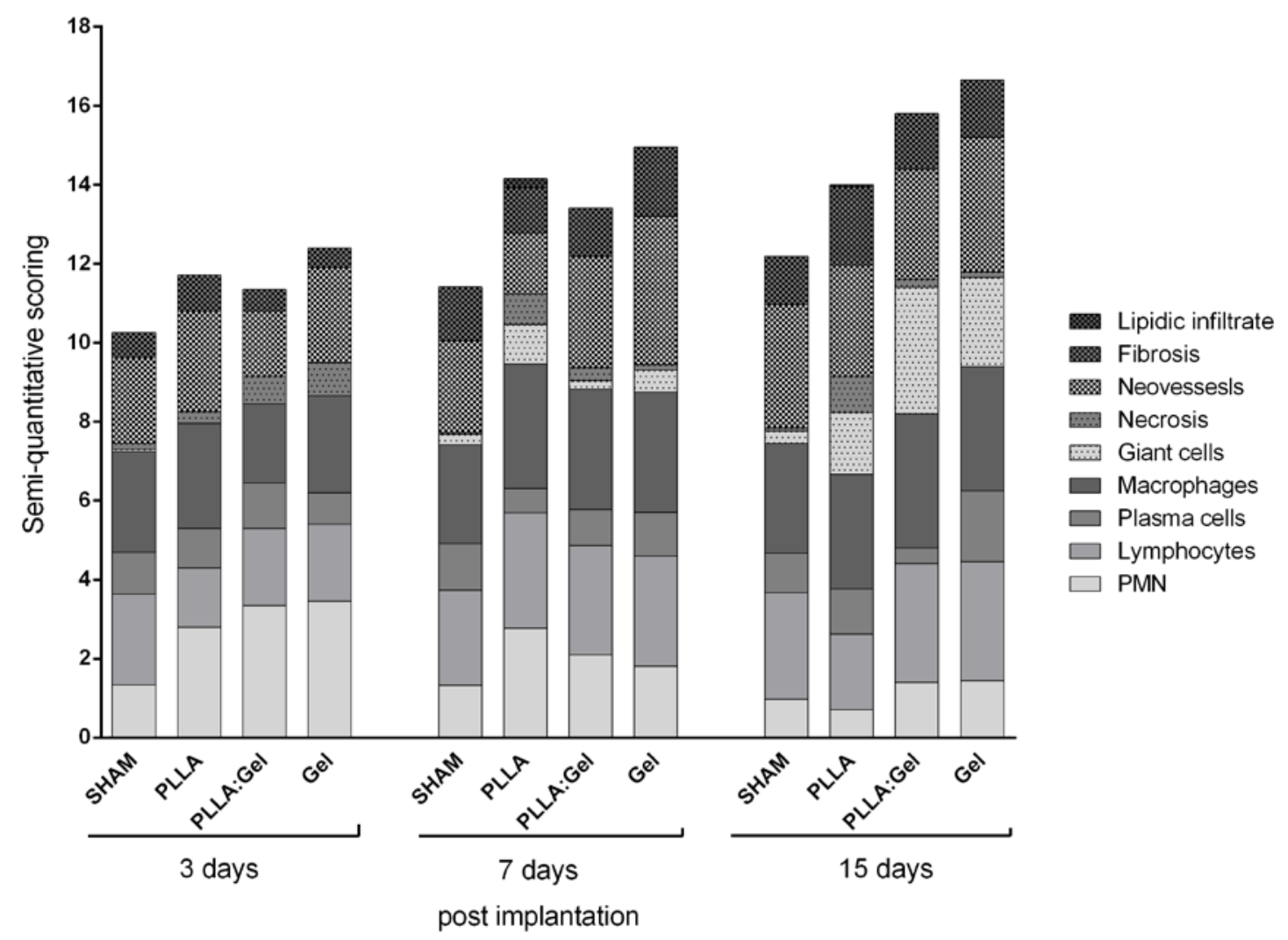

Figure 8: Individual histological parameters of the PLLA, PLLA-GEL and GEL implants after 15 days of subcutaneous implantation versus control surgery sites.

After 15 days of implantation, necropsy examination was performed in all the animals to evaluate potential alterations or systemic effects. The internal organs presented their normal topography, relation and morphological features. All the tissues organs subjected to histological analysis maintained their normal cellular architecture and no alterations compatible with abnormal accumulations, inflammation, necrosis or neoplasia were identified (Figure S2), further supporting the adequate systemic biocompatibility following membrane tissue implantation. 


\section{Conclusions}

This work reports a route to produce electrospun biomimetic membranes from PLLAfish gelatin blends. The wettability and swelling were dramatically changed by increasing gelatin contents present in the electrospun solution, whereas mechanical properties were determined to be in the middle range between the neat PLLA and gelatin membranes.

The membranes cytocompatibility was corroborated in vitro using hUC-MSCs and the inflammatory reaction was measured in a rat animal model by subcutaneous implants, using a microscopic semi-quantitative system. PLLA, PLLA-GEL and GEL electrospun membranes were classified as "slight irritant" after 15 days of subcutaneous implantation, deeming them fit for further biological assays aiming at specific medical applications.

\section{Supporting Information}

The Supporting Information is available free of charge on the ACS Publications website. Representative stress-strain curves and microphotographs of organ histology (PDF)

\section{Acknowledgments}

The authors acknowledge Programa Operacional Regional do Norte (ON.2 - O Novo Norte), QREN, FEDER with the project “iBone Therapies: Terapias inovadoras para a regeneração óssea", ref. NORTE-01-0247-FEDER-003262, and the program COMPETE Programa Operacional Factores de Competitividade, Projects PEstOE/AGR/UI0211/2011 and PEst-C/EME/UI0285/2013 funding from FCT. This research was also supported by Programa Operacional Competitividade e Internacionalização (P2020), Fundos Europeus Estruturais e de Investimento (FEEI) and FCT with the project "BioMate - A novel bio-manufacturing system to produce bioactive scaffolds for tissue engineering" with reference PTDC/EMS-SIS/7032/2014 and by COMPETE 2020, from ANI

- Projectos ID\&T Empresas em Copromoção, Programas Operacionais POCl, by the project "insitu.Biomas - Reinvent biomanufacturing systems by using an usability approach for in situ clinic temporary implants fabrication" with the reference POCl-010247-FEDER-017771. Ana Rita Caseiro (SFRH/BD/101174/2014) acknowledges FCT, for financial support. 


\section{References}

(1) Lyu, S.; Huang, C.; Yang, H.; Zhang, X. Electrospun Fibers as a Scaffolding Platform for Bone Tissue Repair. J. Orthop. Res. 2013, 31 (9), 1382-1389.

(2) Wang, X.; Ding, B.; Li, B. Biomimetic Electrospun Nanofibrous Structures for Tissue Engineering. Mater. Today (Kidlington) 2013, 16 (6), 229-241.

(3) Vacanti, J. P.; Langer, R. Tissue Engineering: The Design and Fabrication of Living Replacement Devices for Surgical Reconstruction and Transplantation. The Lancet 1999, 354, S32-S34.

(4) Tibbitt, M. W.; Anseth, K. S. Hydrogels as Extracellular Matrix Mimics for 3D Cell Culture. Biotechnol. Bioeng. 2009, 103 (4), 655-663.

(5) Daley, W. P.; Peters, S. B.; Larsen, M. Extracellular Matrix Dynamics in Development and Regenerative Medicine. J. Cell Sci. 2008, 121 (Pt 3), 255-264.

(6) Derwin, K. A.; Baker, A. R.; Spragg, R. K.; Leigh, D. R.; lannotti, J. P. Commercial Extracellular Matrix Scaffolds for Rotator Cuff Tendon Repair: Biomechanical, Biochemical, and Cellular Properties. JBJS 2006, 88 (12), 2665-2672.

(7) Badylak, S. F. The Extracellular Matrix as a Biologic Scaffold Material. Biomaterials 2007, 28 (25), 3587-3593.

(8) Badylak, S. F.; Freytes, D. O.; Gilbert, T. W. Extracellular Matrix as a Biological Scaffold Saterial: Structure and Function. Acta Biomater. 2009, 5 (1), 1-13.

(9) Bhatt, R. A.; Rozental, T. D. Bone Graft Substitutes. Hand Clinics 2012, 28 (4), 457468.

(10) Mahmut, P.; Arin, D.; Sedat, O.; Elçin, A. E.; Elçin, Y. M. Clinical Applications of Decellularized Extracellular Matrices for Tissue Engineering and Regenerative Medicine. Biomed. Mater. 2016, 11 (2), 022003.

(11) Gilbert, T. W.; Freund, J. M.; Badylak, S. F. Quantification of DNA in Biologic Scaffold Materials. J. Surg. Res. 2009, 152 (1), 135-139.

(12) Crapo, P. M.; Gilbert, T. W.; Badylak, S. F. An Overview of Tissue and Whole Organ Decellularization Processes. Biomaterials 2011, 32 (12), 3233-3243.

(13) Wang, S.; Hu, F.; Li, J.; Zhang, S.; Shen, M.; Huang, M.; Shi, X. Design of Electrospun Nanofibrous Mats for Osteogenic Differentiation of Mesenchymal Stem Cells. Nanomedicine: NBM 2017, In press 10.1016/j.nano.2016.12.024. 
(14) Valente, T. A. M.; Silva, D. M.; Gomes, P. S.; Fernandes, M. H.; Santos, J. D.; Sencadas, V. Effect of Sterilization Methods on Electrospun Poly(lactic acid) (PLA) Fiber Alignment for Biomedical Applications. ACS Appl. Mater. Interfaces 2016, 8 (5), 32413249.

(15) Santos, D.; Silva, D. M.; Gomes, P. S.; Fernandes, M. H.; Santos, J. D.; Sencadas, V. Multifunctional PLLA-Ceramic Fiber Membranes for Bone Regeneration Applications. J. Colloid Interface Sci. 2017, 504, 101-110.

(16) Yan, Y.; Sencadas, V.; Jin, T.; Huang, X.; Chen, J.; Wei, D.; Jiang, Z. Tailoring the Wettability and Mechanical Properties of Electrospun Poly(L-Lactic Acid)-Poly(Glycerol Sebacate) Core-Shell Membranes for Biomedical Applications. J. Colloid Interface Sci. 2017, 508, 87-94.

(17) Liu, Y.; Ji, Y.; Ghosh, K.; Clark, R. A. F.; Huang, L.; Rafailovich, M. H. Effects of Fiber Orientation and Diameter on the Behavior of Human Dermal Fibroblasts on Electrospun PMMA Scaffolds. J. Biomed. Mater. Res., Part A 2009, $90 A$ (4), 1092-1106.

(18) Lasprilla, A. J. R.; Martinez, G. A. R.; Lunelli, B. H.; Jardini, A. L.; Filho, R. M. Polylactic Acid synthesis for Application in Biomedical Devices - A Review. Biotechnol. Adv. 2012, 30 (1), 321-328.

(19) Saini, P.; Arora, M.; Kumar, M. N. V. R. Poly(Lactic Acid) Blends in Biomedical Applications. Adv. Drug Delivery Rev. 2016, 107, 47-59.

(20) Areias, A. C.; Ribeiro, C.; Sencadas, V.; Garcia-Giralt, N.; Diez-Perez, A.; Gomez Ribelles, J. L.; Lanceros-Mendez, S. Influence of Crystallinity and Fiber Orientation on Hydrophobicity and Biological Response of Poly(L-Lactide) Electrospun Mats. Soft Matter 2012, 8 (21), 5818-5825.

(21) Zhu, X.; Zhong, T.; Huang, R.; Wan, A. Preparation of Hydrophilic Poly(Lactic Acid) Tissue Engineering Scaffold Via (PLA)-(PLA-b-PEG)-(PEG) Solution Casting and ThermalInduced Surface Structural Transformation. J. Biomater. Sci., Polym. Ed. 2015, 26 (17), 1286-1296.

(22) Gregor, A.; Filová, E.; Novák, M.; Kronek, J.; Chlup, H.; Buzgo, M.; Blahnová, V.; Lukášová, V.; Bartoš, M.; Nečas, A.; Hošek, J. Designing of PLA Scaffolds for Bone Tissue Replacement Fabricated by Ordinary Commercial 3D Printer. J. Biol. Eng. 2017, 11 (1), 31. 
(23) Jordá-Vilaplana, A.; Fombuena, V.; García-García, D.; Samper, M. D.; SánchezNácher, L. Surface Modification of Polylactic Acid (PLA) by Air Atmospheric Plasma Treatment. Eur. Polym. J. 2014, 58, 23-33.

(24) Yang, Y.-W.; Wu, J.-Y.; Liu, C.-T.; Liao, G.-C.; Cheng, K.-Y.; Chiang, M.-H.; Wu, J.-S. An Optimized Two-Step Nitrogen-Based Plasma Treatment Procedure under AtmosphericPressure Condition and its Surface Amination Mechanism. Plasma Processes Polym. 2015, 12 (7), 678-690.

(25) Ciardelli, G.; Chiono, V.; Vozzi, G.; Pracella, M.; Ahluwalia, A.; Barbani, N.; Cristallini, C.; Giusti, P. Blends of Poly-( $\varepsilon$-caprolactone) and Polysaccharides in Tissue Engineering Applications. Biomacromolecules 2005, 6 (4), 1961-1976.

(26) Karim, A. A.; Bhat, R. Fish Gelatin: Properties, Challenges, and Prospects as an Alternative to Mammalian Gelatins. Food Hydrocolloids 2009, 23 (3), 563-576.

(27) Zhang, Y. Z.; Venugopal, J.; Huang, Z. M.; Lim, C. T.; Ramakrishna, S. Crosslinking of the Electrospun Gelatin Nanofibers. Polymer 2006, 47 (8), 2911-2917.

(28) Moffa, M.; Polini, A.; Sciancalepore, A. G.; Persano, L.; Mele, E.; Passione, L. G.; Potente, G.; Pisignano, D. Microvascular Endothelial Cell Spreading and Proliferation on Nanofibrous Scaffolds by Polymer Blends with Enhanced Wettability. Soft Matter 2013, 9 (23), 5529-5539.

(29) Zhang, Y.; Ouyang, H.; Lim, C. T.; Ramakrishna, S.; Huang, Z.-M. Electrospinning of Gelatin Fibers and Gelatin/PCL Composite Fibrous Scaffolds. J. Biomed. Mater. Res., Part B 2005, $72 B(1), 156-165$.

(30) Ghasemi-Mobarakeh, L.; Prabhakaran, M. P.; Morshed, M.; Nasr-Esfahani, M.-H.; Ramakrishna, S. Electrospun Poly( $\varepsilon$-Caprolactone)/Gelatin Nanofibrous Scaffolds for Nerve Tissue Engineering. Biomaterials 2008, 29 (34), 4532-4539.

(31) Schnell, E.; Klinkhammer, K.; Balzer, S.; Brook, G.; Klee, D.; Dalton, P.; Mey, J. Guidance of Glial Cell Migration and Axonal Growth on Electrospun Nanofibers of Poly$\varepsilon$-Caprolactone and a Collagen/Poly- $\varepsilon$-Caprolactone Blend. Biomaterials 2007, 28 (19), 3012-3025.

(32) Williams, D. F. On the Mechanisms of Biocompatibility. Biomaterials 2008, 29 (20), 2941-2953.

(33) Diegelmann, F. R.; Evans, C. M. Wound Healing: An Overview of Acute, Fibrotic and Delayed Healing. Front. Biosci. 2004, 9, 283-289. 
(34) Anderson, J. M.; Rodriguez, A.; Chang, D. T. Foreign Body Reaction to Biomaterials. Semin. Immunol. 2008, 20 (2), 86-100.

(35) Kim, H.-W.; Yu, H.-S.; Lee, H.-H. Nanofibrous matrices of poly(lactic acid) and gelatin polymeric blends for the improvement of cellular responses. J. Biomed. Mater. Res. Part A 2008, 87A (1), 25-32.

(36) Gu, S.-Y.; Wang, Z.-M.; Ren, J.; Zhang, C.-Y. Electrospinning of gelatin and gelatin/poly(I-lactide) blend and its characteristics for wound dressing. Mater. Sci. Eng., C 2009, 29 (6), 1822-1828.

(37) Yan, S.; Xiaoquiang, L.; Shuiping, L.; Hongsheng, W.; Chuanglong, H. Fabrication and properties of PLLA-gelatin nanofibers by electrospinning. J. Appl. Polym. Sci. 2010, 117 (1), 542-547.

(38) Chen, J.-P.; Su, C.-H. Surface modification of electrospun PLLA nanofibers by plasma treatment and cationized gelatin immobilization for cartilage tissue engineering. Acta Biomater. 2011, 7 (1), 234-243.

(39) Jaiswal, A. K.; Kadam, S. S.; Soni, V. P.; Bellare, J. R. Improved functionalization of electrospun PLLA/gelatin scaffold by alternate soaking method for bone tissue engineering. Appl. Surf. Sci. 2013, 268, 477-488.

(40) Schneider, C. A.; Rasband, W. S.; Eliceiri, K. W. NIH Image to ImageJ: 25 Years of Image Analysis. Nat. Meth. 2012, 9 (7), 671-675.

(41) International Organisation for Standardization, ISO 10993-6:2016: Biological Evaluation of Medical Devices -- Part 6: Tests for Local Effects After Implantation. International Organization for Standardization: 2016 1-28.

(42) Ramakrishna, S.; Fujijhara, K.; Teo, W.-E.; Lim, T.-C.; Ma, Z. An Introduction to Electrospinning and Nanofibers, World Scientific: 2005.

(43) Correia, D. M.; Ribeiro, C.; Ferreira, J. C. C.; Botelho, G.; Ribelles, J. L. G.; LancerosMéndez, S.; Sencadas, V. Influence of Electrospinning Parameters on Poly(HydroxyButyrate) Electrospun Membranes Fiber Size and Distribution. Polym. Eng. Sci. 2014, 54 (7), 1608-1617.

(44) Lee, J. B.; Ko, Y.-G.; Cho, D.; Park, W. H.; Kwon, O. H. Modification and Optimization of Electrospun Gelatin Sheets by Electron Beam Irradiation for Soft Tissue Engineering. Biomater. Res. 2017, 21 (1), 14. 
(45) Kishan, A. P.; Nezarati, R. M.; Radzicki, C. M.; Renfro, A. L.; Robinson, J. L.; Whitely, M. E.; Cosgriff-Hernandez, E. M. In Situ Crosslinking of Electrospun Gelatin for Improved Fiber Morphology Retention and Tunable Degradation. J. Mater. Chem. B 2015, 3 (40), 7930-7938.

(46) Skotak, M.; Noriega, S.; Larsen, G.; Subramanian, A. Electrospun Cross-Linked Gelatin Fibers With Controlled Diameter: The Effect of Matrix Stiffness on Proliferative and Biosynthetic Activity of Chondrocytes Cultured In Vitro. J. Biomed. Mater. Res., Part A 2010, $95 A(3), 828-836$.

(47) Correia, D. M.; Padrão, J.; Rodrigues, L. R.; Dourado, F.; Lanceros-Méndez, S.; Sencadas, V. Thermal and Hydrolytic Degradation of Electrospun Fish Gelatin Membranes. Polym. Test. 2013, 32 (5), 995-1000.

(48) Farris, S.; Song, J.; Huang, Q. Alternative Reaction Mechanism for the Cross-Linking of Gelatin with Glutaraldehyde. J. Agric. Food Chem. 2010, 58 (2), 998-1003.

(49) Wei, J.; Igarashi, T.; Okumori, N.; Igarashi, T.; Maetani, T.; Liu, B.; Yoshinari, M. Influence of Surface Wettability on Competitive Protein Adsorption and Initial Attachment of Osteoblasts. Biomed. Mater. 2009, 4 (4), 045002.

(50) Lourenço, B. N.; Marchioli, G.; Song, W.; Reis, R. L.; Blitterswijk, C. A. v.; Karperien, M.; Apeldoorn, A. v.; Mano, J. F. Wettability Influences Cell Behavior on Superhydrophobic Surfaces with Different Topographies. Biointerphases 2012, 7 (1), 46. (51) Kaplan, J. A.; Lei, H.; Liu, R.; Padera, R.; Colson, Y. L.; Grinstaff, M. W. Imparting Superhydrophobicity to Biodegradable Poly(lactide-co-glycolide) Electrospun Meshes. Biomacromolecules 2014, 15 (7), 2548-2554.

(52) Ribeiro, C.; Sencadas, V.; Areias, A. C.; Gama, F. M.; Lanceros-Méndez, S. Surface Roughness Dependent Osteoblast and Fibroblast Response on Poly(L-Lactide) Films and Electrospun Membranes. J. Biomed. Mater. Res., Part A 2015, 103 (7), 2260-2268.

(53) Yang, X.; Xu, Q.; Yan, N.; Sui, G.; Cai, Q.; Deng, X. Structure and Wettability Relationship of Coelectrospun Poly(L-Lactic Acid)/Gelatin Composite Fibrous Mats. Polym. Adv. Technol. 2011, 22 (12), 2222-2230.

(54) de Campos Vidal, B.; Mello, M. L. S. Collagen Type I Amide I Band Infrared Spectroscopy. Micron 2011, 42 (3), 283-289. 
(55) Nagiah, N.; Johnson, R.; Anderson, R.; Elliott, W.; Tan, W. Highly Compliant Vascular Grafts with Gelatin-Sheathed Coaxially Structured Nanofibers. Langmuir 2015, 31 (47), 12993-13002.

(56) Zhang, J.; Tsuji, H.; Noda, I.; Ozaki, Y. Structural Changes and Crystallization Dynamics of Poly(I-lactide) During the Cold-Crystallization Process Investigated by Infrared and Two-Dimensional Infrared Correlation Spectroscopy. Macromolecules 2004, 37 (17), 6433-6439.

(57) Pan, P.; Zhu, B.; Kai, W.; Dong, T.; Inoue, Y. Polymorphic Transition in Disordered Poly(I-lactide) Crystals Induced by Annealing at Elevated Temperatures. Macromolecules 2008, 41 (12), 4296-4304.

(58) Nagiah, N.; Madhavi, L.; Anitha, R.; Anandan, C.; Srinivasan, N. T.; Sivagnanam, U. T. Development and Characterization of Coaxially Electrospun Gelatin Coated Poly(3Hydroxybutyric Acid) Thin Films as Potential Scaffolds for Skin Regeneration. Mater. Sci. Eng.: C 2013, 33 (7), 4444-4452.

(59) Yan, Y.; Sencadas, V.; Zhang, J.; Wei, D.; Jiang, Z. Superomniphilic Poly(glycerol sebacate)-Poly(I-lactic acid) Electrospun Membranes for Oil Spill Remediation. Adv. Mater. Interfaces 2017, 4 (20), 1700484.

(60) Huang, Z.-M.; Zhang, Y. Z.; Ramakrishna, S.; Lim, C. T. Electrospinning and Mechanical Characterization of Gelatin Nanofibers. Polymer 2004, 45 (15), 5361-5368.

(61) Torricelli, P.; Gioffrè, M.; Fiorani, A.; Panzavolta, S.; Gualandi, C.; Fini, M.; Focarete, M. L.; Bigi, A. Co-Electrospun Gelatin-Poly(L-Lactic Acid) Scaffolds: Modulation of Mechanical Properties and Chondrocyte Response as a Function of Composition. Mater. Sci. Eng.: C 2014, 36, 130-138.

(62) Deng, K.; Yang, Y.; Ke, Y.; Luo, C.; Liu, M.; Deng, Y.; Tian, Q.; Yuan, Y.; Yuan, T.; Xu, T. A Novel Biomimetic Composite Substitute of PLLA/Gelatin Nanofiber Membrane for Dura Repairing. Neurol. Res. 2017, 39 (9), 819-829.

(63) Wood, W.; Martin, P. Structures in Focus-Filopodia. Int. J. Biochem. Cell Biol. 2002, 34 (7), 726-730.

(64) Ringer, P.; Colo, G.; Fässler, R.; Grashoff, C. Sensing the Mechano-Chemical Properties of the Extracellular Matrix. Matrix Biol. 2017, 64, 6-16.

(65) Parsons, J. T.; Horwitz, A. R.; Schwartz, M. A. Cell Adhesion: Integrating Cytoskeletal Dynamics and Cellular Tension. Nat. Rev. Mol. Cell Biol. 2010, 11 (9), 633-643. 
(66) Anderson, H. J.; Sahoo, J. K.; Ulijn, R. V.; Dalby, M. J. Mesenchymal Stem Cell Fate: Applying Biomaterials for Control of Stem Cell Behavior. Front. Bioeng. Biotechnol. 2016, 4,38 .

(67) Sun, X.; Zheng, R.; Cheng, L.; Zhao, X.; Jin, R.; Zhang, L.; Zhang, Y.; Zhang, Y.; Cui, W. Two-Dimensional Electrospun Nanofibrous Membranes for Promoting Random Skin Flap Survival. RSC Adv. 2016, 6 (11), 9360-9369.

(68) von Recum, H. A.; Cleek, R. L.; Eskin, S. G.; Mikos, A. G. Degradation of Polydispersed Poly(L-Lactic Acid) to Modulate Lactic Acid Release. Biomaterials 1995, 16 (6), 441-447. (69) Zhao, S.; Xie, X.; Pan, G.; Shen, P.; Zhao, J.; Cui, W. Healing Improvement After Rotator Cuff Repair Using Gelatin-Grafted Poly(L-Lactide) Electrospun Fibrous Membranes. J. Surg. Res. 2015, 193 (1), 33-42.

(70) Murice-Lambert, E.; Banford, A. B.; Folger, R. L. Histological Preparation of Implanted Biomaterials for Light Microscopic Evaluation of the Implant-Tissue Interaction. Stain Technol. 1989, 64 (1), 19-24. 